\section{A systematic review of the eclectic approach application in language teaching}

Review of eclectic approach application

Fadi Al-Khasawneh

King Khalid University, Abha, Saudi Arabia

\begin{abstract}
Purpose - This study aimed at providing a systematic review of the research conducted on the application of the eclectic approach in language teaching since 2016.

Design/methodology/approach - The articles have been selected from seven renowned databases (i.e. EBSCO, Online Library, Scopus, ScienceDirect, Sage Journal Online, Education Resources Information Center, and Web of Science). The number of total articles identified in the initial research was 432, out of this number, only 47 articles were selected for the review using predefined inclusion criteria. The selected articles have been analyzed and coded into different categories: research design, location, context, level of education, learning outcomes and pedagogical implications.

Findings - The review analysis showed the major trends and outcomes in the eclectic approach topic. It also provided useful information for stakeholders regarding the application of the eclectic approach in language teaching.
\end{abstract}

Originality/value - The study contributes to some unaddressed points identified in the selected articles, and it recommends some points to be considered in future research.

Keywords Systematic review, The eclectic approach, Language teaching

Paper type Research paper

\section{Introduction}

The theories of English language teaching keep developing to serve the best education for learners and cater to their needs. The history of English language teaching witnessed many attempts to find the most effective approaches for teaching language. Richard and Rodgers (2014) pointed out that language teaching has become a profession on its own in the twentieth century. This profession continues to scout about new issues and the effectiveness of various teaching methods and approaches to overcome those issues. The Grammar-Translation Method was first introduced to be formalized in the classroom. Nonetheless, it receives criticism because of its bilingual strategy to teaching, while language teaching and learning is spontaneous, and learners can use the target language as a medium of instruction.

The criticism on the Grammar-Translation Method has led to developing the Direct Method as a monolingual approach for language teaching. During the 1950s, the Audiolingual Method has been introduced to train military personnel to use oral language. This method became popular in schools, but it was criticized because of its focus on repetitive drills and memorization. Subsequently, the Cognitive Method has emerged, and it mainly focuses on generative grammar and cognitive psychology. This method received much

(C) Fadi Al-Khasawneh. Published in Saudi Journal of Language Studies. Published by Emerald Publishing Limited. This article is published under the Creative Commons Attribution (CC BY 4.0) licence. Anyone may reproduce, distribute, translate and create derivative works of this article (for both commercial and non-commercial purposes), subject to full attribution to the original publication and authors. The full terms of this licence may be seen at http://creativecommons.org/licences/by/4.0/ legalcode

The author extends appreciation to the Deanship of Scientific Research at King Khalid University for funding this work through General Research Project (No: GRP/4/43).

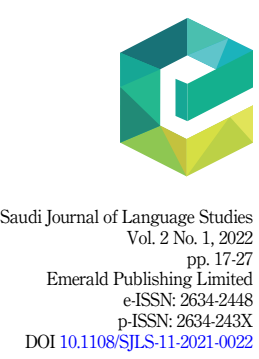

Received 28 November 2021 Revised 22 December 2021 Accepted 15 February 2022 
SJLS

2,1

18

attention among language learners and teachers because it considers learners as active participants regardless of the errors they might commit (Mei, 2018). This method is limited to teaching a language out of the context instead of in-context, thus it has been viewed as a weak teaching approach.

The Situational Teaching Method has been developed and it focuses on teaching and practicing a language in situations. The emergence of this teaching method was seen as a major development in the field of language teaching Gao (2019). However, this method was criticized as it predicts what and how language is used in a specific situation when in fact, language use cannot be predicted (Mwanza, 2020). As a result, the communicative language teaching method evolved in the 1980s. This method received extra attention at that time because it concentrates on language use, regardless of the situation or context. This method is seen as prescriptive and outdated in some contexts because the decisions and methods of language teaching cannot be prescribed. The teaching environment should be dynamic where teachers are encouraged to operate (Mwanza, 2016).

All the developed teaching methods had their strengths and limitations. There was no real and dynamic language teaching method in the classroom setting. This led to the emergence of the eclectic teaching approach which is claimed to be the suitable approach for language teaching. Brown (2002) argues that eclectic approach allows teachers to select the materials that work well in their classrooms within their dynamic contexts. Gilliand et al. (1994) pointed out that the reason for adopting eclecticism is because it does not rely on a single teaching method or approach. The eclectic approach has a broad theoretical basis and has a flexible set of activities. The previous literature on language teaching methods emphasized the importance of investigating the role of eclectic approach in language teaching. However, there is a lack of systematic reviews that shed light on studies investigating the use of the eclectic approach in language teaching. Consequently, this study aims at reporting the different studies that investigated the use of eclecticism as an approach for language teaching. It also aims at studying the different trends of the research done in the last few years.

\section{Research questions}

The present systematic review is based on one general research question: What are the trends in the studies done on the use of the eclectic approach in language teaching? The general question of this study has been associated with the following sub-questions:

(1) What are the major methodologies identified?

(2) What are the learning outcomes identified?

(3) What are the contexts used for language teaching?

(4) What are the major similarities and differences in the obtained results?

(5) What are the identified gaps in the reviewed studies?

\section{Theoretical background}

The eclectic approach is a teaching style used in teaching a second or a foreign language. This approach combines the principles of various methods and approaches of teaching a language depending on the lesson objectives and individual differences of students (Iscan, 2017). According to Kumar (2013), the eclectic theory of language teaching has emerged in the 1990s as an additional theory of language teaching. The eclectic approach becomes popular because it contributes to achieving the learning objectives without much pressure on both teachers and learners. The eclectic approach helps in having a clearer vision for learners of what they 
are learning. Teaching with this approach includes but is not limited to using multiple tasks, lively learning and high interaction between students and teachers. Larsen-Freeman (2000) emphasized the importance of the eclectic approach in teaching. In her point of view, the eclectic approach is pluralistic, consistent and entails diverse learning activities that match with learners' needs.

According to Gao (2011), the principles of eclectic approach would challenge instructors to ensure that decisions about classroom instruction and activities are based on a holistic and comprehensive understanding of all teaching theories and pedagogies, in terms of the goal and situation of language teaching and learning, learners' needs, the available materials and how language is learned. Gao (2011) viewed eclecticism as a teaching method that combines all language skills (e.g. listening, speaking, reading and writing) and encompasses some practice in the classroom. He also advises teachers to integrate and take advantage of all other teaching methods and to avoid their disadvantages. Wali (2009) stated that principled eclecticism should not serve methods but learners. Thus, it is up to the teachers' discretion to choose procedures and techniques inside the classroom. Each one of the language teaching methods has its own advantages and disadvantages, and there is no concrete or ideal approach in language teaching. The eclectic teaching approach is characterized by keen flexibility since teachers can choose whatever works to achieve learning objectives (Wali, 2009).

It is extremely important to note that the eclectic approach is not rigorous, and its features are combined with other teaching methods. Ali (1981) attempted to explain the major characteristics and principles of eclecticism as follows:

(1) Teachers are free to select various types of teaching techniques in the classroom with reference to the lesson objectives.

(2) Teachers could choose any method or aspect that suits teaching inside the classroom.

(3) Learners will see different teaching aids that make lessons more stimulating and interesting.

(4) Teachers and learners would be in a better situation to overcome difficulties that may arise from the textbook materials.

(5) The eclectic approach saves much time and effort in the presentation of language activities.

(6) The eclectic approach is subjective since it is constructed by teachers according to the learning context.

In a similar vein, Parupalli (2018) indicated some prominent features of eclecticism as follows:

(1) Eclecticism makes teaching more enjoyable and innovative.

(2) It enhances the active interaction between students and teachers.

(3) Caters to the individual needs of learners.

(4) Enhances practical teaching as it facilitates retention and builds self-confidence.

(5) Eclecticism enables instructors to achieve the learning objectives easily.

(6) It is a problem-based approach to teaching languages that solves the problems encountered by the students in class.

(7) Testing is not a separate element but a part of this approach.

(8) Learners would have a clear vision of what they are learning.
Review of eclectic approach application 
SJLS

2,1

(9) This approach includes various tasks such as higher interaction, lively learning, correlative learning and fast results.

(10) Eclecticism connects life experiences of learners to the ideas presented in language learning.

The teacher should carefully select the materials to suit the learning context and make the teaching process more motivating and interesting. Widemann (2001) affirmed that good teachers spend much time in collecting attractive and interesting teaching materials to gladden their teaching. Teachers should not spare a thought in developing materials for the learners. In eclectic approach, teachers can use computers, pictures, maps, music, film, radio, newspapers, magazines, textbooks, research articles, chats and realia in their teaching (Ledema, 2003).

Jewitt (2005) pointed out that more teaching materials have significantly entered the classroom in the twenty-first century, such as sound, image and movement. Duncum (2004) stated that teaching can be meaningful in the classroom through the interaction of spoken voice, sound effects, music and pictures. This implicates using a variety of resources appropriate to the learning objectives, and not be limited to speech. Therefore, eclectic teachers should be creative in using materials and objects, for example, teachers can use pictures and movements to teach English verb tenses.

Like any other teaching method, the eclectic teaching approach has advantages and disadvantages. The eclectic approach is live, motivating, participatory, context-sensitive, learner-centered and includes using a variety of classroom tasks and activities. In addition, the eclectic approach is flexible to the needs of the classroom during the lesson, it is correlative and objective since it addresses the learners' needs of diverse backgrounds (Kumar, 2013). The eclectic approach is said to have disadvantages that include (1) discouraging teachers to reflect upon their teaching; (2) The adoption of the eclectic approach could be unsafe due to the methodological baggage that comes with it. Nonetheless, the eclectic approach is more advantageous than disadvantageous; most of the limitations of this approach are justifiable when teachers are poorly prepared for the classroom (Widemann, 2001).

\section{Methodology}

The data of this study have been collected through searching in electronic journals and databases. The selected databases for this systematic review include EBSCO, Wiley Online Library, Scopus, ScienceDirect, SAGE Journal Online, Education Resources Information Center (ERIC), and Web of Science. The searched terms used for this review include "the eclectic approach," "eclecticism," "the eclectic approach and language teaching" and "eclecticism in language teaching." The previous input would allow the databases to look for any kind of combination between the eclectic approach and language teaching.

\section{Inclusion criteria}

The present review adopted certain criteria for articles selection and inclusion. The criteria include the following:

(1) The article must be an empirical study.

(2) The article has explicitly investigated the eclectic approach in language teaching.

(3) The article must have been published in conference proceedings or journals between 2016 and 2021. This time frame was specified to review the most recent research of the topic under investigation. 
(4) The articles must be written in the English language.

(5) The articles must contain an abstract. This is very important to select relevant research manuscripts.

(6) The present review concentrates on the use of the eclectic approach in teaching the English language; thus, any article that investigates the use of the eclectic approach in teaching other subjects will be excluded.

\section{Review of eclectic approach application}

\section{The selected articles}

The total number of selected articles for this review was 432 . This number has considerably been reduced after the inclusion and exclusion criteria to 47 articles (Table 1).

The table above shows that most of the articles selected after applying inclusion and exclusion criteria were from ERIC database 15 (31.91\%), followed by EBSCO database 9 (19.14\%), Wiley Online Library 7 (14.89\%), Scopus 6 (12.76\%), SAGE Journal Online 5 $(10.63 \%)$, ScienceDirect $4(8.51 \%)$ and Web of Science $1(2.12 \%)$. All the articles that did not meet the criteria were excluded and the main reason for elimination is that they are not empirical studies or written in other languages.

\section{Data analysis}

The selected articles that fulfilled the inclusion criteria were coded according to the following:

(1) Research design: how was the article designed to address the research questions.

(2) Location: this includes the country where the study was conducted.

(3) Context: this explains the context of investigation in the classroom, out of the classroom, both in the classroom and out of the classroom.

(4) Level: this involves the educational level of the selected participants for each article.

(5) Learning outcomes: this code shows the impact/effect of the eclectic approach in language teaching.

(6) Pedagogical implications: to determine the pedagogical activities in which the eclectic approach could be used to support language teaching.

\section{Results and discussion}

This section presents the research design used in the selected articles. As shown in Table 2, the most used research design was quasi-experimental 14 articles $(29.79 \%)$, followed by

\begin{tabular}{lcrr}
\hline Database & $\begin{array}{c}\text { Number of selected articles } \\
\text { Initial number }\end{array}$ & After inclusion criteria \\
\cline { 1 - 2 } EBSCO & 98 & 9 & \\
Wiley online library & 52 & 7 & \\
Scopus & 59 & 6 & Table 1. \\
ScienceDirect & 51 & 4 & The number of selected \\
SAGE journal online & 37 & 15 & articles beforeand after \\
ERIC & 102 & 1 & applying inclusion and \\
Web of Science & 33 & 47 & exclusion criteria \\
Total & 432 & & 5 \\
\hline
\end{tabular}


SJLS

2,1

\section{2}

Research design used in the selected articles

mixed methods 12 articles (25.54\%), survey 9 articles $(19.15 \%)$ and both qualitative and experimental used in 6 articles each $(12.76 \%)$.

\section{Location}

Table 3 shows that most of the studies have been conducted in India with 11 studies $(23.40 \%)$, followed by Saudi Arabia 8 (17.04\%), Indonesia 7 (14.89\%), Malaysia 6 (12.76), Kenya 3 $(6.41 \%), 2$ studies conducted in Zambia, Pakistan and Palestine $(4.26 \%)$ for each country, and only 1 study conducted in Sri Lanka, Sudan, Uzbekistan, Libya, Sweden and Ecuador $(2.12 \%)$ for each country.

\section{Article context}

The information in Table 4 shows that most of the studies have been conducted in the classroom with 24 studies $(51.07 \%)$, followed by the studies conducted in the classroom and out of the classroom with 16 studies $(34.04 \%)$ and studies conducted out of the classroom with only 7 studies $(14.89 \%)$.

\begin{tabular}{lcc}
\hline Research design & Frequency & Percentage \\
\hline Quasi-experimental & 14 & 29.79 \\
Mixed methods & 12 & 25.54 \\
Quantitative & 9 & 19.15 \\
Qualitative & 6 & 12.76 \\
Experimental & 6 & 12.76 \\
Total & 47 & 100 \\
\hline
\end{tabular}

\begin{tabular}{lcc}
\hline Country & Frequency & Percentage \\
\hline India & 11 & 23.40 \\
Saudi Arabia & 8 & 17.04 \\
Indonesia & 7 & 14.89 \\
Malaysia & 6 & 12.76 \\
Kenya & 3 & 6.41 \\
Zambia & 2 & 4.26 \\
Pakistan & 2 & 4.26 \\
Palestine & 2 & 4.26 \\
Sri Lanka & 1 & 2.12 \\
Sudan & 1 & 2.12 \\
Uzbekistan & 1 & 2.12 \\
Libya & 1 & 2.12 \\
Sweden & 1 & 2.12 \\
Ecuador & 1 & 2.12 \\
Total & 47 & 100 \\
\hline
\end{tabular}

Table 3.

The location where the selected articles have been conducted

\begin{tabular}{lcc}
\hline Context & Frequency & Percentage \\
\hline In classroom & 24 & 51.07 \\
In the classroom and out of the classroom & 16 & 34.04 \\
Out of classroom & 7 & 14.89 \\
Total & 47 & 100 \\
\hline
\end{tabular}


Level of education

The data obtained in this study show that 21 articles involved participants enrolled in secondary schools 21 (44.68\%), followed by participants enrolled in higher education 19 $(40.43 \%)$ and participants enrolled in primary education $7(14.89 \%)$ (see Table 5).

\section{Learning outcomes}

The learning outcomes obtained from the selected articles have been coded and grouped into six different categories: (1) Positive effect on achievement and retention (AR), (2) acquisition of language skills (ALS), (3) increase learners' motivation (LM), (4) active participation (AP), (5) build confidence (BC) and (6) positive learning emotions (PLE). Table 6 shows the frequency of learning outcomes mentioned in the selected articles.

The positive effect on achievement and retention (AR) was the most frequent learning outcome and it was found in 13 articles $(27.66 \%)$, followed by Acquisition of language skills (ALS) 11 articles (23.41\%), Increase learners' motivation (LM) 8 articles (17.02\%), Active participation (AP) 8 articles (17.02\%), Build confidence (BC) 5 articles (10.63\%), and Positive learning emotions (PLE) with 2 articles (4.26\%). The following presents example extracts for each of the above-mentioned outcomes.

(1) Positive effect on achievement and retention (AR)

... the findings revealed that the eclectic learning approach has a positive effect on students' academic achievement and retention in English at the elementary level.

... the use of EM enhances effective learning of English as more knowledge/information is retained for a long time.

(2) Acquisition of language skills (ALS)

... it integrates all the four language skills of listening, speaking, reading, and writing.

... considering the students' needs, teaching and introducing contextual grammar and vocabulary, and integrating all language skills.

\section{Review of eclectic approach application}


SJLS

2,1

\section{4}

(3) Increase learners' motivation (LM)

... the use of ECLC, creates an enjoyable learning atmosphere, without boredom and the interest and motivation level of the student rises as a result.

... it increases the motivation of students to learn foreign languages.

... while doing the task, it made active participation of the individual learners.

... the use of eclectic approach increases the participation of learners and their involvement in learning tasks.

(5) Build confidence (BC)

... this Method was very effective and helped to develop confidence in the learners to speak in a target language.

(6) Positive learning emotions (PLE)

... the students will be motivated to express their emotions and share their experiences without any inhibitions.

\section{Pedagogical implications}

The pedagogical implications found in the selected articles concentrated on three major points: (1) Adoption of the eclectic approach for teaching (AEAT), (2) Explicit training for teachers (ETT) and (3) Adoption of learner-centered curriculum (ALCC). Table 7 shows the frequency of pedagogical implications mentioned in the selected articles.

The adoption of the eclectic approach for teaching (AEAT) was the most frequent pedagogical implication and it was mentioned in 29 articles $(61.70 \%)$, followed by explicit training for teachers (ETT), 16 articles (34.04\%), and adoption of learner-centered curriculum (ALCC), 2 articles $(4.26 \%)$. The following are sample extracts of the pedagogical implications mentioned in the articles.

(1) Adoption of the eclectic approach for teaching (AEAT)

... it is strongly recommended that elementary school teachers should adopt the eclectic learning approach for teaching English as it is more effective, flexible, and useful.

Table 7.

Pedagogical implications of using the eclectic approach

\begin{tabular}{lcc}
\hline Pedagogical implications & Frequency & Percentage \\
\hline Adoption of the eclectic approach for teaching (AEAT) & 29 & 61.70 \\
Explicit training for teachers (ETT) & 16 & 34.04 \\
Adoption of learner-centered curriculum (ALCC) & 2 & 4.26 \\
Total & 47 & 100 \\
\hline
\end{tabular}


... the adoption of the eclectic approach serves the learning purpose and encourages the students to learn the language systematically.

... it is indispensable to choose an efficacious method like the Eclectic Method to teach English effectively in an EFL classroom.

(2) Explicit training for teachers (ETT)

... there is a need for language teachers to be taken for in-service training courses regularly to improve the teacher's method of class instruction.

... the problem could be solved through qualified training for teachers, especially in undergraduate and graduate programs.

\section{(3) Adoption of learner-centered curriculum (ALCC)}

... the results of this empirical study, recommend a learner-centered curriculum to enhance language learning in the classroom.

\section{The similarities and differences in the selected articles}

The systematic review of the eclectic approach in language teaching shows some similarities and differences between the selected articles. It is obvious that most of the articles used quasi-experimental and mixed methods as a research design. Other articles used surveys, qualitative, or experimental research designs. Most of the studies have been conducted in Asia (38) articles, followed by Africa with 7 studies, South America with 1 study and Europe with 1 study. Most of the studies have been conducted in classroom (24) studies followed by studies conducted in and out of classroom (16) studies and out of classroom (7) studies.

Most of the participants in the selected articles were from secondary schools (21) studies, followed by participants from higher education (19) studies and participants from primary education (7) studies. The selected articles studied the eclectic approach in language teaching from different perspectives. However, all the studies come to a consensus that the use of the eclectic approach has a positive impact on enhancing the learning of a second or foreign language. The studies emphasized on combining different techniques and activities in the learning process. They viewed the eclectic approach as collaborative learning and they all agreed that learning in groups would be beneficial for the students, creating a more enjoyable and motivating environment.

Most of the studies recommend the adoption of the eclectic approach due to its importance to avoid boredom in the class and accurately address the learning objectives. These studies recommended engaging teachers in explicit training to adopt the eclectic approach successfully. Only two studies recommended shifting to a learner-centered curriculum in which students will be responsible for their learning and teachers' role is limited to guidance and direction.

\section{What are the gaps not addressed in the reviewed studies?}

The current review has explored the research conducted on the eclectic approach in language teaching. It was apparent that the studies conducted in South America and Europe have been minimal. Consequently, there is a persistent need to conduct more studies in these regions to get clearer insights into the impact of the eclectic approach on language teaching. Most of the

\section{Review of eclectic approach application}

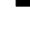


SJLS

2,1

reviewed studies have been conducted on students from secondary and tertiary levels. Very few studies have focused on students from the elementary level.

The reviewed studies have mainly focused on the use/impact of the eclectic approach on the teaching of the English language in general. However, it is very important to investigate the applications of the eclectic approach in the teaching of specific language components such as grammar, reading, writing, listening or speaking. It will be very useful to explore how teachers apply this approach to teach specific language components.

Most of the studies have focused on examining the impact of applying the eclectic approach in teaching particular topics and/or lessons. Hence, it would be a very good idea to investigate and observe teachers in a long-time span to check whether or not, teachers are eclectic in every lesson. There is also a need to conduct comparative studies between public and private schools in the use and impact of the eclectic approach on students' performance. These comparative studies could also include students' level as a variable when studying the impact of the eclectic approach on language teaching. All the aforementioned points could bridge the gaps on this topic and provide more insights and clearer pictures for students, teachers, curriculum and policymakers.

\section{Conclusion}

This review study sheds light on the research on the use of the eclectic approach in language teaching which is mainly representative and up to date. This systematic review was very useful to determine the major trends and outcomes of the use of the eclectic approach in language teaching. All the selected articles have been coded carefully to detect their research design, location, context, level of education, learning outcomes and pedagogical implications. The similarities and differences between the selected articles have been synthesized along with the gaps not addressed on this topic. The area of the eclectic approach is very rich and worthy to be further investigated. Future studies can be useful to explain in detail the impact of applying the eclectic approach on teaching language components. The pedagogical implications of the future studies would enhance the performance of students and bridge the underrepresented language learning.

\section{References}

Ali, A.M. (1981), Teaching English to Arab Students, Al-Falah House, Jordan.

Brown, H. (2002), "English language teaching in the 'post-method' era: toward better diagnosis, treatment, and assessment", in Richards, J. and Renandya, W. (Eds), Methodology in Language Teaching: An Anthology of Current Practice, Cambridge Professional Learning, Cambridge University Press, Cambridge, pp. 9-18, doi: 10.1017/CBO9780511667190.003.

Duncum, P. (2004), "Visual culture isn't just visual: multiliteracy, multimodality and meaning”, Studies in Art Education, Vol. 45 No. 3, pp. 252-264, doi: 10.1080/00393541.2004.11651771.

Gaao, L. (2019), "Research on the role of situational teaching in second language teaching", Universe Scientific Publishing, Vol. 3 No. 2, pp. 59-62, available at: https://ojs.usp-pl.com/index.php/ ADVANCES-IN-HIGHER-EDUCATION/article/view/1412/1277.

Gao, L. (2011), "Eclecticism or principled eclecticism", Creative Education, Vol. 2 No. 4, pp. 363-369, doi: 10.4236/ce.2011.24051.

Gilliland, B.E., James, R.K. and Bowman, J.T. (1994), "Response to the lazarus and Beutler article 'on technical eclecticism"', Journal of Counseling and Development, Vol. 72 No. 5, pp. 554-555, doi: 10.1002/j.1556-6676.1994.tb00991.x.

Iscan, A. (2017), "The use of eclectic method in teaching Turkish to foreign students", Journal of Education and Practice, Vol. 8 No. 7, pp. 149-153, available at: https://eric.ed.gov/? $\mathrm{id}=\mathrm{EJ} 1137580$. 
Jewitt, C. (2005), "Multimodality, 'reading', and 'writing' for the 21st century", Discourse, Studies in the Cultural Politics of Education, Vol. 26 No. 3, pp. 315-331, doi: 10.1080/01596300500200011.

Kumar, C.P. (2013), "The eclectic method-theory and its application to the learning of English", International Journal of Scientific and Research Publications, Vol. 3 No. 6, pp. 1-4, available at: http://www.ijsrp.org/research-paper-0613/ijsrp-p1844.pdf.

Larsen-Freeman, D. (2000), Techniques and Principles in Language Teaching, 2nd ed., Oxford University Press, New York, available at: https://www.uobabylon.edu.iq/eprints/publication_3_ 8715_1861.pdf.

Ledema, R. (2003), "Multimodality, resemiotization: extending the analysis of discourse as multisemiotic practice", Visual Communication, Vol. 2 No. 1, pp. 29-57, doi: 10.1177/ 1470357203002001751.

Mei, Y. (2018), "Comments on the audiolingual method", International Journal of Arts and Commerce, Vol. 7 No. 4, p. 90, available at: https://www.ijac.org.uk/images/frontImages/gallery/Vol.7No.4/5. 47-53.pdf.

Mwanza, D.S. (2016), "A critical reflection on eclecticism in the teaching of english grammar at selected Zambian secondary schools", unpublished $\mathrm{PhD}$ thesis, University of Western Cape, available at: https://core.ac.uk/download/pdf/58915854.pdf.

Mwanza, D.S. (2020), "An analysis of teachers classroom application of the eclectic method to English language teaching in multilingual Zambia", International Journal of Research and Innovation in Social Science, Vol. 4 No. 2, pp. 260-275, available at: http://dspace.unza.zm/bitstream/handle/ 123456789/7145/Article \%202.pdf?sequence $=1 \&$ isAllowed $=\mathrm{y}$.

Parupalli, R.S. (2018), "Eclectic approach in English language teaching: a comprehensive study", ACADEMICIA: An International Multidisciplinary Research Journal, Vol. 8 No. 10, p. 40, doi: 10. 5958/2249-7137.2018.00055.1.

Richards, J.C. and Rodgers, T.S. (2014), Approaches and Methods in Language Teaching, Cambridge University Press, available at: https:/www.novaconcursos.com.br/blog/pdf/richards-jack-c.\&-rodgers.pdf.

Wali, N.H. (2009), "Eclecticism and language learning", Al-Fatih Journal, Vol. 39, pp. 1-8, available at: https://www.iasj.net/iasj/download/42fa7770a7d4de12.

Weidemann, A. (2001), "The old and the new: reconsidering eclecticism in language teaching", Per Linguam, Vol. 17 No. 1, pp. 1-13, doi: 10.5785/17-1-131.

\section{Corresponding author}

Fadi Al-Khasawneh can be contacted at: falkhasoneh@kku.edu.sa
Review of eclectic approach application 